\title{
A new universal simplified adhesive: 6-month randomized multi-center clinical trial
}

\author{
Elisa Gomes de Albuquerque, ${ }^{1}$ Flavio Warol, ${ }^{1}$ Fernanda Signorelli Calazans, ${ }^{1}$ Luiz Augusto Poubel, ${ }^{1}$ Stella Soares Marins, ${ }^{1}$ Thalita Matos, ${ }^{2}$ Taise Hanzen, ${ }^{2}$ \\ Marcos de Oliveira Barceleiro, ${ }^{1}$ Alessandro Dourado Loguercio ${ }^{2}$ \\ ${ }^{1}$ Department of Operative Dentistry, School of Dentistry, Federal Fluminense University (UFF), Nova Friburgo, RJ, Brazil \\ ${ }^{2}$ Department of Operative Dentistry, Ponta Grossa State University, Ponta Grossa, PR, Brazil \\ - Conflicts of interest: none declared.
}

\section{Abstract}

Objective: the objective of this multi-center double-blind, randomized clinical trial was to evaluate the clinical performance of a new universal adhesive system (Futurabond U, Voco GbmH, Germany) when applied using different application strategies over a period of six months. Material and Methods: for this, 200 restorations were performed on non-carious cervical lesions using the adhesive Futurabond $U$ according to four adhesive strategies $(n=50$ per group): self-etch without previous conditioner (SEE); self-etch associated with selective enamel etching (SET); etch-and-rinse with dry dentin (ERDry) and; etch-and-rinse with wet dentin (ERWet). After hybridization, cavities were restored using Admira Fusion composite resin (Voco $\mathrm{GmbH}$ ). After 6 months of clinical performance, these restorations were evaluated according to FDI criteria in the following items: retention/fracture, marginal adaptation, marginal staining, postoperative sensitivity and caries recurrence. Results: seven restorations were lost/fractured after six months of clinical evaluation (2 in the SEE group, 1 in the SET group, 1 in the ERDry group, and 3 in the ERWet group). The retention rates for six months (95\% confidence interval) were $96 \%$ (86\%-98\%) for the SEE group, $98 \%$ ( $89 \%-99 \%$ ) for the SET group, $98 \%$ (89\%-99\%) for the ERDry group and 94\% (83\%-97\%) for the ERWet group, with no statistical difference identified between any pair of groups ( $p>0.05)$. Twenty-four restorations presented small marginal adaptation defects at the six-months evaluation recall, and all of them were considered clinically acceptable. Conclusion: the clinical performance of the universal adhesive Futurabond $U$ associated to Admira Fusion unidoses resin composite was found to be promise after 6 -month of clinical evaluation when applied in non-carious cervical lesions and it was not depending on the bonding strategy employed.

Keywords: Adhesive techniques; Self etching; Dental restorations; Clinical longevity.

\section{Introduction}

$\mathbf{T}$ he simplification of daily clinical procedures in dental practice represents an excellent gain for the dentist. ${ }^{1}$ Based on this idea, the evolution of the adhesive systems was also conceived with the objective of reducing the operative steps, reducing clinical time, and facilitating the application technique without impairing the stability of the adhesive interface over time. $^{2}$

A good example of simplification is the development of self-etch adhesive systems that allowed, through partial infiltration and/or modification of the smear layer, the penetration of resinous monomers into the intraand inter-tubular dentin, forming a hybrid layer with fewer defects compared to etch-and-rinse adhesive systems, ${ }^{3}$ therefore making this layer more resistant to degradation. ${ }^{4}$ This is only possible due to the fact that self-etch adhesives eliminate the acid etching of dentin in a separate step. However, the enamel conditioning pattern is lower when using a self-etch adhesive. ${ }^{5}$ To overcome this situation, the selective enamel-etching technique is recommended when self-etch adhesives are recommended. ${ }^{6}$ Unfortunately, when phosphoric acid is applied to the enamel and inadvertently flows into the dentin, the dentin-bonding results of the selfetch adhesive could be affected. ${ }^{7,8}$

Trying to improve the versatility during the application of adhesive systems, especially considering the different clinical situations (for example, cavities with or without the presence of enamel), universal adhesive systems have recently been developed, with the proposal that the same adhesive bottle could be used associated or not with the previous application of phosphoric acid ${ }^{9-11}$ without compromising the effectiveness of bonding when applied to dentin or enamel ${ }^{12,13}$ and, thus, can replace the existing simplified adhesives (onestep self-etch and two-step etch-and-rinse). This is only possible because universal adhesives contain monomers that promote chemical adhesion to enamel and dentin in their composition., ${ }^{9,10,12}$ So, they can be used as self-etch adhesives with and without the association of selective enamel etching. In addition, manufacturers have also asserted that, whenever the dentist choose the etch-and-rinse technique, after acid is rinsed out of dentin, and dentin is dried, adhesion may be made on wet or dry dentin, which is certainly another interesting simplification for dentists when this process is used in the etch-and-rinse strategy.

Although several universal adhesives have already been evaluated in in vitro tests to establish the best application protocol for universal adhesives, and though these studies showed reliable results, ${ }^{9,12-14}$ it is known that only clinical evaluations are the ultimate proof of clinical efficacy. ${ }^{15}$ Unfortunately, clinical studies with universal adhesive systems have shown controversial results, and they are still restricted to two universal adhesives, which shows that other universal adhesives and their different application techniques still have to be evaluated..$^{16-19}$ Therefore, the objective of this multi-center, double-blind, randomized clinical trial was to evaluate the clinical behavior of a new universal adhesive (Futurabond U, Voco GbmH, Cuxhauer, Germany) when applied using different application strategies during six months of clinical evaluation. The null 
hypothesis tested was that bonding to NCCLs using the SE strategy - regardless of whether or not it is associated with selective enamel etching or using the ER strategy - applied on dry or moist dentin would result in similar retention levels over six months of clinical service.

\section{Material and Methods}

\section{Study Design}

The description of the experimental design followed the Consolidated Standards of Reporting Trials (CONSORT) statement. ${ }^{20}$ The Universidade Estadual de Ponta Grossa (protocol 165.357; 2016) and the Universidade Federal Fluminense - Polo de Nova Friburgo (protocol 1.618.895; 2016), ethics committees reviewed and approved the protocol and issued a consent form for this study. Written informed consent was obtained from all participants prior to starting the study. This clinical trial was registered in clinicaltrial. gov clinical registry (\#NCT03244124). All participants were informed about the nature and objectives of the study, but they were not aware of which tooth received the specific treatments under evaluation.

This was a multi-center double-blind randomized clin- ical trial that used a superiority, method. The study was carried out in the clinics of the School of Dentistry at Universidade Federal Fluminense (Nova Friburgo, RJ, Brazil) and Universidade Estadual de Ponta Grossa (Ponta Grossa, PR, Brazil) between October 2016 and November 2016. The authors decided to form a sample of convenience, and no advertisement was made for participant recruitment. While patients were searching for treatment in the clinics of both universities, they were informed about the research and, once they understood the objectives of the study, and signed the informed consent, they were recruited to the study.

\section{Eligibility Criteria}

A total of 120 participants were examined by two calibrated dental residents to check if they met the inclusion and exclusion criteria at each university (Figure 1). Clinical examination was performed with a mouth mirror, a number 5 explorer, and a periodontal probe. Participants had to be in good general health, be at least 18 years old, have an acceptable oral hygiene level, and present at least 20 teeth under occlusion.

To be included in the stydy, participants had to have at least four non-carious cervical lesions (NCCLs), that should

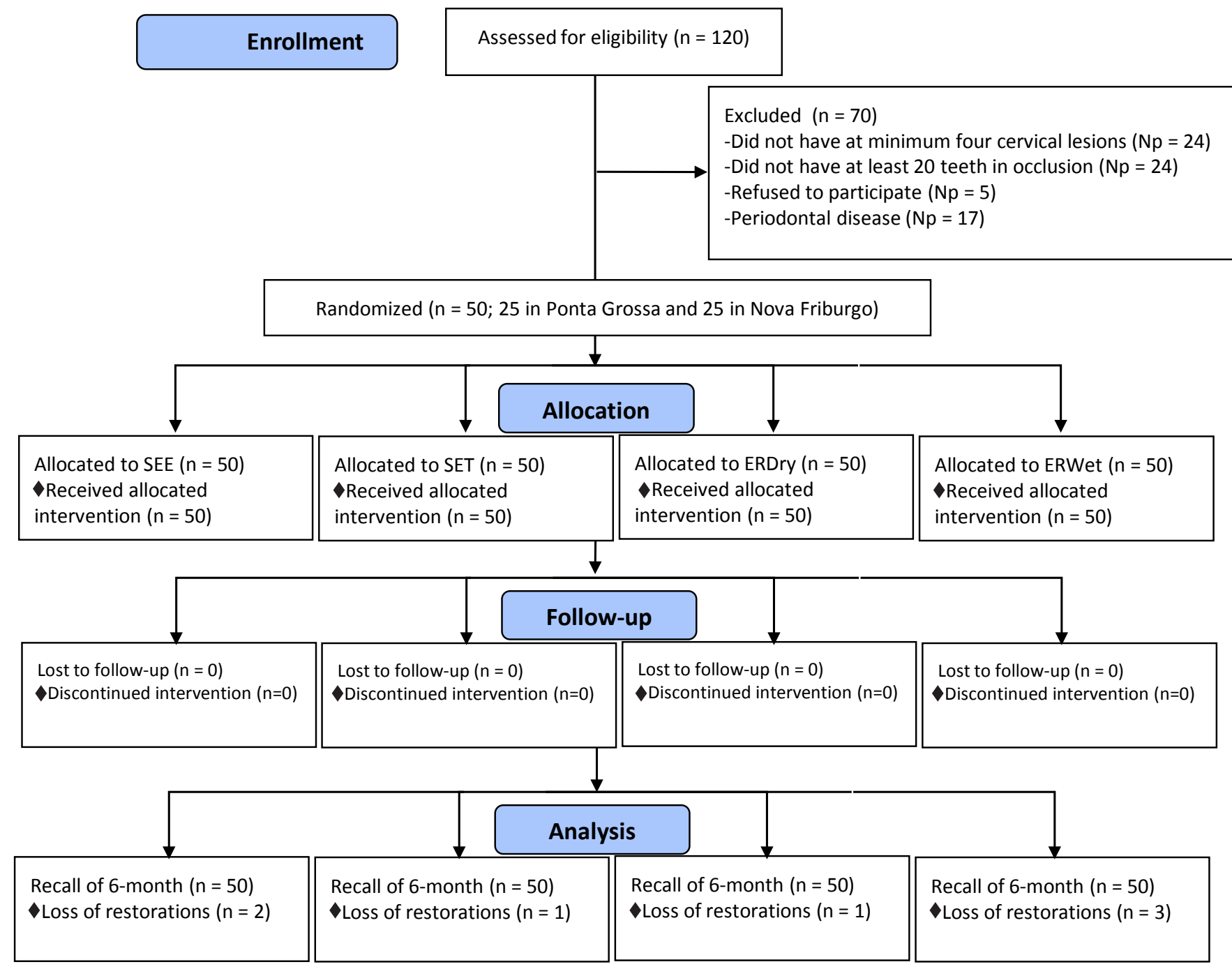

Figure 1. Flow chart of the study design 
be non-retentive, deeper than $1 \mathrm{~mm}$, and involve both the enamel and dentin of vital teeth without mobility, in four different teeth. The cavosurface margin could not involve more that $50 \%$ of enamel, ${ }^{21}$ as shown in Figure 2a e 2b. Patients with extremely poor oral hygiene or who used orthodontic devices, had severe or chronic periodontitis, or had heavy bruxism habits were excluded from the study, as they would receive other treatments before restorative intervention. Also, participants with known allergies to resin-based materials or any other material used in this study, who were pregnant or breastfeeding women, or participants under chronic use of anti-inflammatory, analgesic, and psychotropic drugs were not included in the study. After the screening sessions, 50 patients were selected, and 200 teeth were randomized into four different groups.
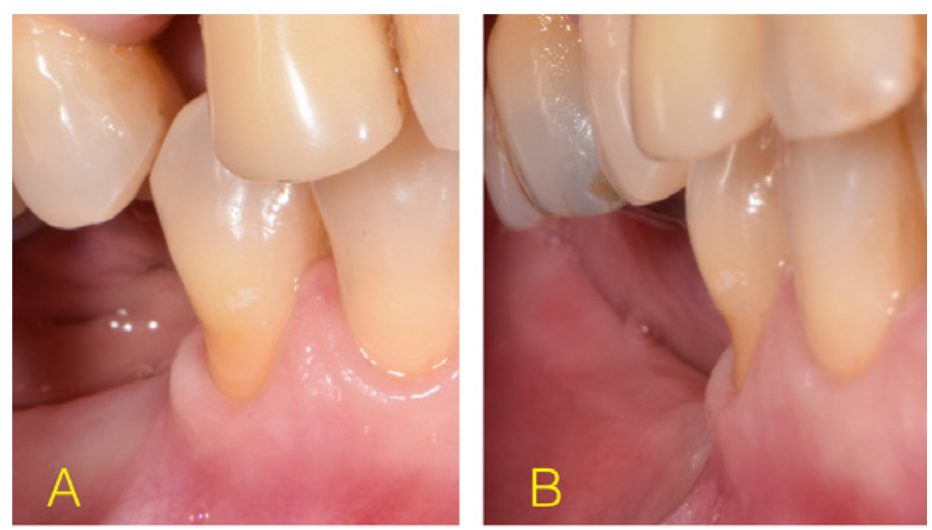

Figure 2. Initial aspect of non-carious cervical lesion: A. Vestibular view. B. Lateral view

\section{Sample Size Calculation and Randomization}

In a recent systematic review, ${ }^{22}$ the annual retention failure rate to one-step self-etch adhesives in NCCLs was reported to be $4.4 \%$. Considering that this data follows a linear trend, the overall retention rate of these adhesive systems will be of approximately $78 \%$ after five years of clinical service. Then, considering an Type I error of $5 \%(\alpha=0.05)$, a type II error of $20 \%(\beta=80 \%)$, and a two-sided test, the minimal sample size was calculated to be of 50 restorations in each group to detect a difference of $25 \%$ among the test groups.

The randomization was done on an intra-individual basis so that each subject ended up with four restorations, each one resulting from one of all possible combinations of adhesive strategies. These randomization schemes were performed using the software available at http://www.sealedenvelope.com.
A staff member not involved in the research protocol performed the randomization process with computer-generated tables.

\section{Interventions: Restorative Procedure}

All the patients selected for this study received dental prophylaxis with a suspension of pumice and water in a rubber cup and signed an informed consent form two weeks before the restorative procedures. The degree of sclerotic dentin from the NCCLs was measured according to the criteria described by Swift et al. ${ }^{23}$ and was classified in categories 1 (no sclerosis present) to 4 (significant sclerosis present). The cavity dimensions in millimeters (height, width, and depth), the geometry of the cavity (evaluated by profile photograph and labeled at $<45^{\circ}, 45^{\circ}-90^{\circ}, 90^{\circ}<135^{\circ}$, and $>$ $\left.135^{\circ}\right),{ }^{24}$ the presence of an antagonist, and the presence of attrition facets were observed and recorded. Pre-operative sensitivity was also evaluated by applying air for $10 \mathrm{~s}$ from a dental syringe placed $2 \mathrm{~cm}$ from the tooth's surface and by applying it with an explorer. These features were recorded to allow comparison of the baseline features of the dentin cavities among experimental groups.

To calibrate the restorative procedure, the study director in each center placed one restoration of each group in one patient to identify all steps involved in the application technique. Then, the four operators, who were resident dentists with more than five years of clinical experience in operative dentistry-two in each center-placed four restorations, one of each group, under the supervision of the study director in a clinical setting. The restoration failures were shown to the operators prior to starting the study. At this point, the operators were considered calibrated to perform the restorative procedures. The operators restored all teeth included in the study. All participants received four restorations, one of each experimental group in different lesions previously selected according to the inclusion criteria.

Before restorative procedures, the patients received dental local anaesthesia using 3\% mepivacaine solution (Mepisv, Nova DFL, Rio de Janeiro, RJ, Brazil). Operators cleaned all lesions with pumice and water in a rubber cup (ref \#8040RA and \#8045RA, KG Sorensen, Barueri, SP, Brazil), followed by rinsing and drying. Then, shade selection was made using a shade guide. After a rubber dam was placed, the new universal adhesive system Futurabond U (Voco, GmbH, Cuxhaven, Germany) was applied as described below. The compositions, application modes, and batch numbers are described in Table 1 and Table 2.

Table 1. Composition and batch number of materials used in the restorative procedures

\begin{tabular}{|c|c|c|}
\hline Material (Manufacturer) & Batch Number & Composition \\
\hline $\begin{array}{l}\text { Futurabond U } \\
\text { (VOCO GmbH, Cuxhaven, Germany) }\end{array}$ & 1609415 & $\begin{array}{l}\text { 35\% Phosphoric acid (Vococid): } 35 \% \text { Phosphoric Acid } \\
\text { Adhesive: HEMA, Bis-GMA, HEDMA, acidic adhesive monomer }\left({ }^{*}\right) \text {, urethane } \\
\text { dimethacrylate, catalyst, silica nanoparticles, ethanol }\end{array}$ \\
\hline $\begin{array}{l}\text { Admira Fusion } \\
\text { (VOCO GmbH, Cuxhaven, Germany) }\end{array}$ & $\begin{array}{l}\text { - shade A2: } 1607524 \\
\text { - shade A3: } 1606252 \\
\text { - shade A3,5: } 1605482\end{array}$ & $\begin{array}{l}\text { Resin matrix: aromatic and aliphatic dimethacrylates, methacrylate-function- } \\
\text { alized polysiloxane } \\
\text { Inorganic filler: Ba-Al-glass, pyrogenic } \mathrm{SiO}_{2} \text {, filler load: } 78 \% \text { mass. Photoiniti- } \\
\text { ator: camphorquinone. Synergist: } \mathrm{NI}\end{array}$ \\
\hline
\end{tabular}

Abbreviations: HEMA: 2-hydroxyethyl methacrylate; Bis-GMA: Bisphenol-A-glycidyl dimethacrylate; HEDMA: 1,6-hexanediol dimethacrylate; (*) Acidic adhesive monomer in the composition of Futurabond $U$ is 10-MDP: 10-methacryloyloxydecyl dihydrogen phosphate according to personal communication with Dr. Martin Danebrock 
Table 2. Application mode of the adhesive system in the groups $\left(^{*}\right)$

\begin{tabular}{|c|c|c|c|c|}
\hline \multirow{3}{*}{$\begin{array}{r}\text { Group } \\
\text { Self-etch (SEE) }\end{array}$} & \multicolumn{4}{|c|}{ Application mode } \\
\hline & \multicolumn{2}{|c|}{ Etch } & Adhesive & Resin composite \\
\hline & No & & \multirow{4}{*}{$\begin{array}{l}\text { 1. Activate single dose } \\
\text { adhesive package; } \\
\text { 2. Apply adhesive to the } \\
\text { cavity surface with Voco } \\
\text { Single Tim Brush for } 20 \mathrm{~s} \\
\text { with vigorous agitation; } \\
\text { 3. Gently air thin for } 5 \mathrm{~s} ; \\
\text { 4. Light cure for } 10 \mathrm{~s} \text { at } \\
\text { 1200 } \mathrm{mW} / \mathrm{cm}^{2} \text {. }\end{array}$} & \multirow{4}{*}{$\begin{array}{l}\text { Insert in the cavity } \\
\text { increases of up to } 1 \mathrm{~mm} \\
\text { and light-cure each area of } \\
\text { the surface of the resto- } \\
\text { ration with a dental curing } \\
\text { light appliance (wave- } \\
\text { length of } 470 \mathrm{~nm} \text {, light } \\
\text { power of } 1200 \mathrm{~mW} / \mathrm{cm}^{2} \text { ) } \\
\text { for } 30 \mathrm{~s} \text {. }\end{array}$} \\
\hline $\begin{array}{l}\text { Self-etch associated } \\
\text { to selective enamel } \\
\text { etching (SET) }\end{array}$ & $\begin{array}{l}\text { Apply etchant ONLY in } \\
\text { enamel (30s), rinse for } \\
30 \text { s, air dry to remove } \\
\text { excess of water }\end{array}$ & $\begin{array}{l}\text { Keep dentin dry (do } \\
\text { not overdry) }\end{array}$ & & \\
\hline $\begin{array}{l}\text { Etch-and-rinse, } \\
\text { dentin dry (ERDry) }\left(^{* *}\right)\end{array}$ & \multirow{2}{*}{$\begin{array}{l}\text { Apply etchant in ena- } \\
\text { mel (30s) and dentin } \\
(15 \mathrm{~s}) \text {, rinse for } 30 \text { s, air } \\
\text { dry to remove excess } \\
\text { of water }\end{array}$} & & & \\
\hline $\begin{array}{l}\text { Etch-and-rinse, } \\
\text { dentin wet (ERWet) }\end{array}$ & & Keep dentin wet & & \\
\hline
\end{tabular}

(*) According to the manufacturer's instructions.

$\left.{ }^{(* *}\right)$ Manufacturer does not indicate application in dry dentin.

- Self-etch associated with selective enamel etching group (SET) - The 35\% phosphoric acid (Vococid, Voco GmbH, Cuxhaven, Germany) was applied for 30 s only in enamel (Figure 3a). Then, cavities were rinsed and air dried, keeping the dentin visibly dry (Figure $3 \mathrm{~b}$ ). The single-dose adhesive system package was activated (Figure $3 c$ and $3 d$ ),
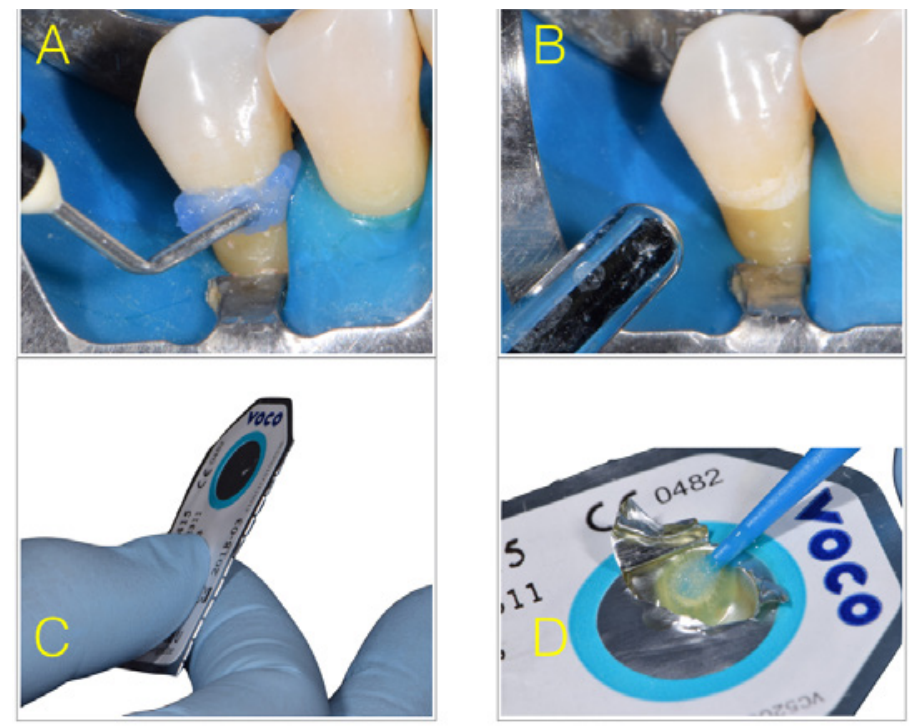

Figure 3. Restorative procedure: A. Selective enamel etching. B. After rinsed and air-dried cavity. C. Single dose adhesive system package being activated. D. Adhesive system ready to be applied and then one coat of adhesive was gently scrubbed on the entire enamel and dentin surface for approximately $20 \mathrm{~s}$, according to the manufacturer's recommendations (Table 2) (Figure 4a). The adhesive was then evaporated by gentle air stream for $5 \mathrm{~s}$ and light cured for $10 \mathrm{~s}$ at $1200 \mathrm{~mW} / \mathrm{cm}^{2}$ (Bluephase, Ivoclar Vivadent, Schaan, Liechtenstein).
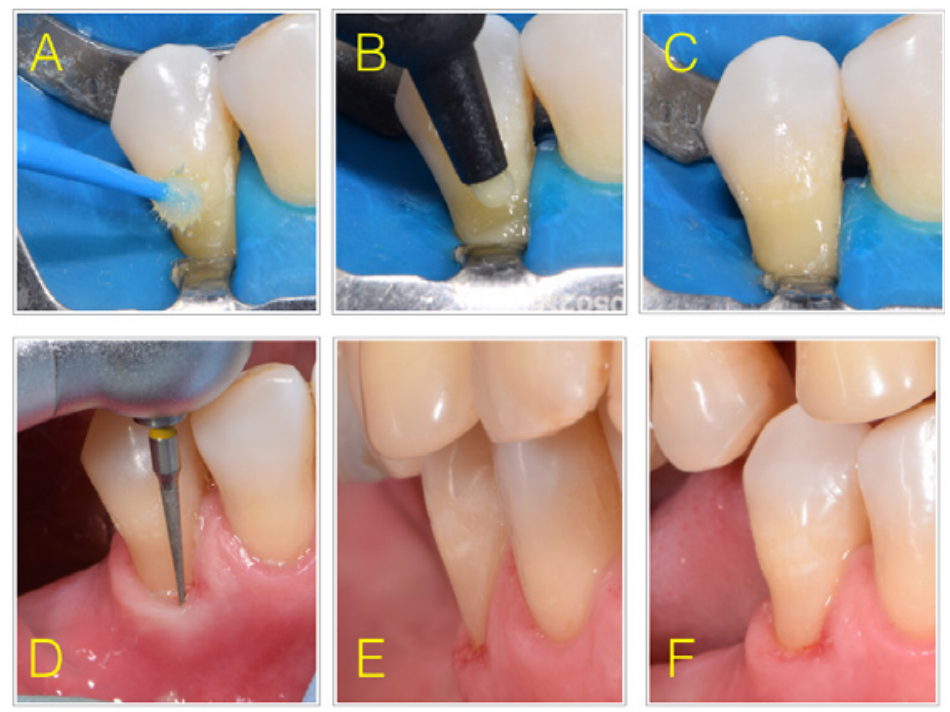

Figure 4. Restorative procedure: A. Adhesive system being applied for $20 \mathrm{~s}$ with vigorous agitation on enamel and dentin. B. Composite resin unidose being applied in the cavity. C. Composite resin restoration after place last increment and light cured. D. Restoration being finished. E. Restoration finished; Immediate aspect; Lateral view. F. Restoration finished; Immediate aspect; Vestibular view 
- Self-etch without previous etching group (SEE) - One coat of adhesive was gently scrubbed on the entire enamel and dentin surface for approximately $20 \mathrm{~s}$, according to the manufacturer's recommendations (Table 2). Solvent-evaporation and light-curing procedures were similar to the sequence described in the SET group.

- Etch-and-rinse dry dentin group (ERDry) - The 35\% phosphoric acid (Vococid) was applied for $30 \mathrm{~s}$ (enamel) and $15 \mathrm{~s}$ (dentin). Then, cavities were rinsed and air dried, keeping the dentin visibly dry. The adhesive system was applied as described in the SET group (Table 2). Solvent evaporation and light curing procedures were also the same.

- Etch-and-rinse wet dentin group (ERWet) [CONTROL GROUP]_- The 35\% phosphoric acid (Vococid) was applied for $30 \mathrm{~s}$ (enamel) and $15 \mathrm{~s}$ (dentin). Then, cavities were rinsed and slightly air dried, keeping the dentin visibly moist. The adhesive system was applied as described in the SET group (Table 2). Solvent evaporation and light curing procedures were also the same.

After adhesive application, the resin composite Admira Fusion unidoses (Voco GmbH, Cuxhaven, Germany) was used in up to three increments, inserted directly in the cavity with Centrix device, and each one was light cured for $10 \mathrm{~s}$ at $1200 \mathrm{~mW} / \mathrm{cm}^{2}$ (Bluephase, Ivoclar Vivadent, Schaan, Liechtenstein) (Figure $4 \mathrm{~b}$ and Figure 4c). The restorations were finished immediately with fine and extra-fine \#2200 diamond burs (KG Sorensen, Barueri, SP, Brazil) (Figure 4d) and polished with Jiffy polisher (Ultradent, South Jordan, Utah, USA) under constant water cooling (Figures $4 \mathrm{e}$ and Figure 4f).

\section{Blinding}

The two examiners, who performed the clinical evaluation, were not involved or present during the clinical procedures, which means that they were blinded to group assignment. Patients were also blinded to group assignment, and didn't know which teeth received each treatment. So, this study followed a double-blind randomized clinical trial design.

\section{Clinical Evaluation}

The examiners evaluated the restorations following the World Federation criteria (FDI) ${ }^{25,26}$ at baseline and after six months. Examiners were kept blind to earlier evaluations during the follow-up recalls.

Following the FDI criteria, the primary outcome was restoration retention and fracture, and the secondary outcomes were marginal staining, marginal adapta- tion, postoperative sensitivity, and recurrence of caries. Spontaneous postoperative sensitivity evaluation was performed seven days after the restorative procedure. Patients were asked if they experienced any pain during the seven days period.

These variables were ranked according to FDI criteria and placed into categories: clinically very good, clinically good, clinically sufficient/satisfactory, clinically unsatisfactory but repairable, and clinically poor (replacement required). ${ }^{25,26}$ Both examiners evaluated all the restorations once and independently. When disagreements occurred during the evaluations, the examiners had to reach a consensus before the participant was dismissed. The restoration retention rates were calculated according to ADA guidelines. ${ }^{27}$ Cumulative failure percentage $=[(\mathrm{PF}+\mathrm{NF}) /(\mathrm{PF}+\mathrm{RR})] \mathrm{X} 100 \%$, where $\mathrm{PF}$ is the number of previous failures before the current recall, NF is the number of new failures during the current recall, and $\mathrm{R} R$ is the number of currently recalled restorations.

\section{Statistical Analysis}

The statistical analyses followed the intention-to-treat protocol according to CONSORT's (Consolidated Standards of Reporting Trials) suggestion. ${ }^{20}$ Descriptive statistics were used to describe the distributions of the evaluated criteria. A statistical analysis for each individual item was performed for FDI evaluation criteria. The differences in the ratings of the four groups after 6 months were tested with the Friedman repeated-measures analysis of variance by rank $(\alpha=0.05)$. Cohen's kappa statistics were used to test inter-examiner agreement. In all statistical tests, the authors pre-set the level of significance to $5 \%$.

\section{Results}

The restorative procedures were implemented exactly as planned, and no modification was performed. Seventy out of 120 patients examined for eligibility were not enrolled in the study because they did not fulfill the inclusion criteria. Thus, a total of 50 subjects ( 23 men and 27 women) were selected. Two hundred restorations were placed: 50 for each group (Figure 1). All baseline details relative to the research subjects and characteristics of the restored lesions are displayed in Table 3. The overall Cohen kappa statistics showed excellent agreement between the examiners during the six-month (0.94) follow-up recall. All research subjects were evaluated at baseline and at the six-month recall. 
Table 3. Characteristics of the research subjects and the non-carious cervical lesions (NCCL) per each experimental group ( ${ }^{*}$ )

\begin{tabular}{|c|c|c|c|c|}
\hline Characteristics of research subjects & Number of patients & & & \\
\hline \multicolumn{5}{|l|}{ Gender distribution } \\
\hline Male & 23 & & & \\
\hline Female & 27 & & & \\
\hline \multicolumn{5}{|l|}{ Age distribution (years) } \\
\hline $20-29$ & 3 & & & \\
\hline $30-39$ & 3 & & & \\
\hline $39-49$ & 20 & & & \\
\hline$>49$ & 24 & & & \\
\hline \multirow[t]{2}{*}{ Characteristics of NCCLs lesions } & \multicolumn{4}{|c|}{ Number of lesions } \\
\hline & SEE & SET & ERDry & ERWet \\
\hline \multicolumn{5}{|l|}{ Shape (degree of angle) } \\
\hline$<45$ & 0 & 0 & 0 & 0 \\
\hline $45-90$ & 8 & 10 & 13 & 6 \\
\hline $90-135$ & 17 & 13 & 15 & 17 \\
\hline$>135$ & 25 & 27 & 22 & 27 \\
\hline \multicolumn{5}{|l|}{ Cervico-incisal height (mm) } \\
\hline$<1.5$ & 14 & 17 & 17 & 15 \\
\hline $1.5-2.5$ & 15 & 13 & 14 & 17 \\
\hline $2.5-4.0$ & 12 & 8 & 12 & 11 \\
\hline$>4.0$ & 9 & 12 & 7 & 7 \\
\hline \multicolumn{5}{|l|}{ Degree of sclerotic dentin } \\
\hline 1 & 29 & 28 & 28 & 31 \\
\hline 2 & 13 & 14 & 11 & 11 \\
\hline 3 & 6 & 7 & 9 & 6 \\
\hline 4 & 2 & 1 & 2 & 2 \\
\hline \multicolumn{5}{|l|}{ Presence of antagonist } \\
\hline Yes & 41 & 39 & 42 & 44 \\
\hline No & 9 & 1 & 8 & 6 \\
\hline \multicolumn{5}{|l|}{ Attrition facet } \\
\hline Yes & 37 & 38 & 40 & 43 \\
\hline No & 13 & 12 & 10 & 7 \\
\hline \multicolumn{5}{|l|}{ Pre-operative sensitivity (spontaneous) } \\
\hline Yes & 13 & 11 & 11 & 13 \\
\hline No & 37 & 39 & 39 & 37 \\
\hline \multicolumn{5}{|l|}{ Pre-operative sensitivity (air dry) } \\
\hline Yes & 17 & 13 & 13 & 15 \\
\hline No & 33 & 37 & 37 & 35 \\
\hline \multicolumn{5}{|l|}{ Tooth distribution } \\
\hline \multicolumn{5}{|l|}{ Anterior } \\
\hline Incisor & 9 & 12 & 10 & 11 \\
\hline Canines & 8 & 5 & 10 & 9 \\
\hline \multicolumn{5}{|l|}{ Posterior } \\
\hline Premolar & 21 & 24 & 23 & 21 \\
\hline Molar & 12 & 9 & 7 & 9 \\
\hline \multicolumn{5}{|l|}{ Arc distribution } \\
\hline Maxillary & 25 & 27 & 24 & 26 \\
\hline Mandibular & 25 & 23 & 26 & 24 \\
\hline
\end{tabular}

(*) SEE, self-etch without any previous etching; SET, self-etch with selective enamel etching; ERWet, etch-and-rinse, wet dentin; ERDry, etch-and-rinse, dry dentin

256 Rev Bras Odontol. 2017;74(4):251-60 


\section{Retention/Fracture}

Seven restorations were lost or fractured after six months of clinical evaluation (two for SEE, one for SET, one for ERDry, and three for ERWet; Table 4). According to FDI evaluation criteria, the six-month retention rates $(95 \%$ confidence interval [CI]) were 96\% (86\%-98\%) for SEE, 98\% (89\%-99\%) for SET, 98\% (89\%-99\%) for ERDry, and 94\% (83\%-97\%) for ERWet, with no statistical difference identified between any pair of groups ( $p>0.05$; Table 4$)$.

\section{Marginal Adaptation}

Twenty-four restorations were considered to have minor discrepancies in marginal adaptation at the sixmonth recall using the FDI criteria ( 8 for SEE, 9 for SET, 4 for ERDry, and 3 for ERWet; Table 4). No significant difference was detected between any pair of groups at the six-month recall ( $\mathrm{p}>0.05$; Table 4$)$.

Table 4. Number of evaluated restorations for each experimental group (*) classified according to the World Dental Federation (FDI) criteria ${ }^{25,26}$

\begin{tabular}{|c|c|c|c|c|c|c|c|c|c|}
\hline \multirow{2}{*}{ FDI Criteria } & \multirow{2}{*}{$(* *)$} & \multicolumn{4}{|c|}{ Baseline } & \multicolumn{4}{|c|}{ Six months } \\
\hline & & SEE & SET & ERWet & ERDry & SEE & SET & ERDry & ERWet \\
\hline \multirow{5}{*}{ Marginal staining } & A & 50 & 50 & 50 & 50 & 48 & 49 & 49 & 47 \\
\hline & $\mathrm{B}$ & -- & -- & -- & -- & -- & -- & -- & -- \\
\hline & $C$ & -- & -- & -- & -- & -- & -- & -- & -- \\
\hline & $\mathrm{D}$ & -- & -- & -- & -- & -- & -- & -- & -- \\
\hline & $E$ & -- & -- & -- & -- & -- & -- & -- & -- \\
\hline \multirow{5}{*}{$\begin{array}{l}\text { Fractures and } \\
\text { retention }\end{array}$} & $A$ & 50 & 50 & 50 & 50 & 48 & 49 & 49 & 47 \\
\hline & B & -- & -- & -- & -- & -- & -- & -- & -- \\
\hline & $C$ & -- & -- & -- & -- & -- & -- & -- & -- \\
\hline & D & -- & -- & -- & -- & -- & -- & -- & 01 \\
\hline & $\mathrm{E}$ & -- & -- & -- & -- & 02 & 01 & 01 & 02 \\
\hline \multirow{5}{*}{ Marginal adaptation } & A & 50 & 50 & 50 & 50 & 40 & 40 & 45 & 44 \\
\hline & B & -- & -- & -- & -- & 08 & 09 & 04 & 03 \\
\hline & $C$ & -- & -- & -- & -- & -- & -- & -- & -- \\
\hline & D & -- & -- & -- & -- & -- & -- & -- & -- \\
\hline & $E$ & -- & -- & -- & -- & -- & -- & -- & -- \\
\hline \multirow{5}{*}{$\begin{array}{l}\text { Post-operative } \\
\text { (hyper-) sensitivity }\end{array}$} & $A$ & 50 & 50 & 50 & 50 & 48 & 49 & 49 & 47 \\
\hline & $\mathrm{B}$ & -- & -- & -- & -- & -- & -- & -- & -- \\
\hline & $C$ & -- & -- & -- & -- & -- & -- & -- & -- \\
\hline & D & -- & -- & -- & -- & -- & -- & -- & -- \\
\hline & $\mathrm{E}$ & -- & -- & -- & -- & -- & -- & -- & -- \\
\hline \multirow{5}{*}{ Recurrence of caries } & A & 50 & 50 & 50 & 50 & 48 & 49 & 49 & 47 \\
\hline & $\mathrm{B}$ & -- & -- & -- & -- & -- & -- & -- & -- \\
\hline & $C$ & -- & -- & -- & -- & -- & -- & -- & -- \\
\hline & D & -- & -- & -- & -- & -- & -- & -- & -- \\
\hline & $E$ & -- & -- & -- & -- & -- & -- & -- & -- \\
\hline
\end{tabular}

$\left.{ }^{*}\right)$ SEE, self-etch without any previous etching; SET, self-etch with selective enamel etching; ERWet, etch-and-rinse, wet dentin; ERDry, etch-and-rinse, dry dentin.

$\left.{ }^{(* *}\right)$ A = Clinically very good; B = Clinically good; C = Clinically sufficient / satisfactory; $D=$ Clinically unsatisfactory; $E=$ Clinically poor. 


\section{Other Parameters}

No restorations had postoperative sensitivity to air at the six-month recall using FDI criteria. Marginal discoloration was not observed in any restorations in FDI criteria. No restoration showed recurrence of caries after six months for FDI criteria. Usually, the restorations showed a very good clinical performance, which can be seen in Figure 5, after 6 months of clinical performance.

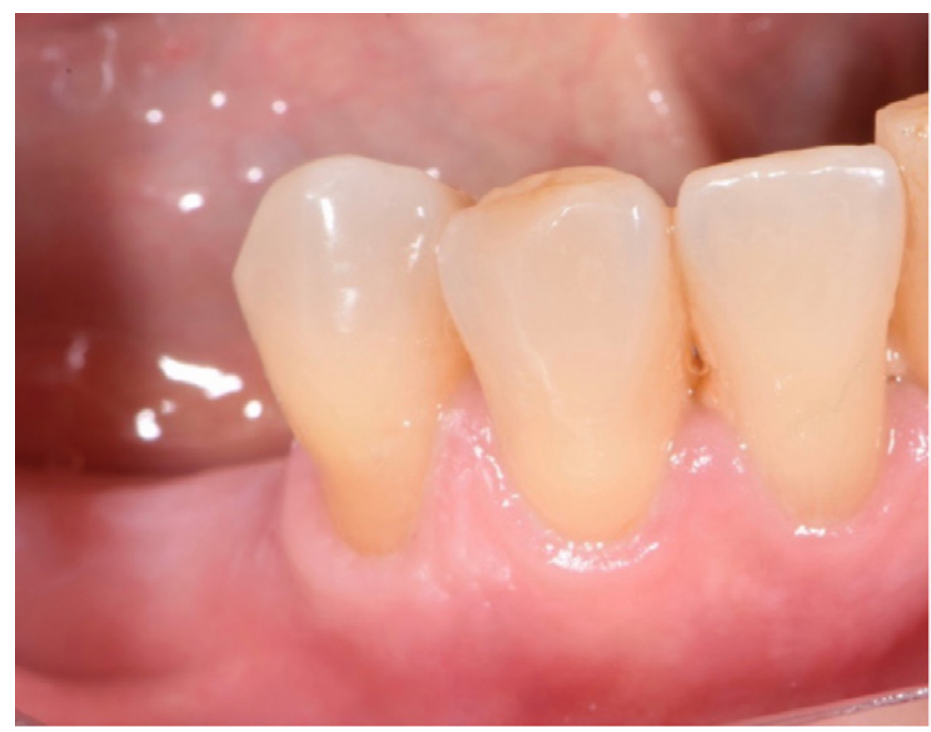

Figure 5. Restoration after 6-month of clinical evaluation

\section{Discussion}

Adhesion to dental tissues is one of the greatest challenges still present in adhesive dentistry, and manufacturers of dental materials are continually seeking solutions to increase the clinical longevity of adhesive restorations. ${ }^{2}$

Two-step etch-and-rinse adhesive systems have been used for many years, and several problems are associated with their application technique. During dentin acid etching, the demineralized collagen fibers may collapse after air drying, leading to a decrease in bond strength. ${ }^{28}$ Therefore, the maintenance of moist or wet dentin is necessary, but without water excesses, which could also prevent the correct infiltration of the resinous monomers. ${ }^{29}$ However, methods for moisture control of the dentin surface and for maintaining the original structure of collagen fibrils are highly subjective and technique sensitive, ${ }^{30}$ which leads to a large number of failures during the formation of the hybrid layer. $^{31}$ These failures may lead to accelerated degradation of the adhesive layer and may thereby undermine the longevity of adhesive restorations. ${ }^{32,33}$

However, no significant difference was observed when the ERDry and ERWet groups were compared. Although this fact seems novel, in fact, no previous clinical study comparing dentin moisture with the older two-step etchand-rinse adhesives found any difference when dentin was kept moist or dry during an evaluation period of up to two years. ${ }^{21,34,35}$ Same results were also recently demonstrated for two universal adhesive systems. ${ }^{16,18,19}$ This fact may lead us to conclude that dentin moisture does not appear to in- fluence clinical outcomes. However, longer studies (at least five years) are necessary to draw more informed conclusions about this clinical situation. It is worth to note the extremely low percentage of restorations that showed failures in these two groups (ERDry and ERWet), similar to two other recently evaluated universal adhesive systems (Single Bond Universal, 3MESPE ${ }^{16,17}$ and Xeno Select, Dentsply ${ }^{19}$ ). This testifies to the quality of the Futurabond U system when applied in conjunction with acid etching of the dentin.

However, using the universal adhesive systems, such as self-etch adhesives, is one way of making the technique more simplified and, consequently, less sensitive to the operator. ${ }^{2}$ A well known problem of self-etch adhesives over time is the low bonding rate to the enamel, which can be solved with the selective enamel-etching technique. ${ }^{5,6}$ For this reason, the majority of the manufacturer's recommendations for universal adhesive systems indicate the technique of selective enamel etching prior to the application of the adhesive to the enamel and dentin.

The clinical results in terms of the retention of Futurabond $\mathrm{U}$ in these two groups (SEE and SET) were very good after 6 months of clinical evaluation, with a success rate of 96\%-98\%. Despite the short clinical evaluation, a recently published clinical study that evaluated the universal adhesive system Xeno Select (Dentsply) ${ }^{19}$ demonstrated a retention percentage of $80 \%-85 \%$ when applied in these same techniques, lower than the result of the present investigation. In other words, the good clinical results of the present study could not be attributed to the short clinical evaluation, but to the composition of Futurabond $U$.

In fact, the success rates of Futurabond $U$ have shown similarity to those of another universal adhesive system (Single Bond Universal, 3M ESPE) after six months of clinical performance. ${ }^{16,17}$ In the Mena-Serrano's ${ }^{16}$ study, the percentage of success ranged from $94 \%-100 \%$ for SEE and SET and in Lawson's one; ${ }^{17}$ it was $97 \%$ (only SEE group was evaluated). These results are probably related to the presence of the 10MDP acidic functional monomer (10-methacryloyloxydecyl dihydrogen phosphate). ${ }^{36}$ This functional monomer is responsible for the formation of a stable salt with hydroxyapatite calcium from dentin. The stability of this calcium salt has been correlated with the high bond strength of 10-MDP to enamel and dentin immediately and after storage in water. ${ }^{37}$ Although the safety data sheet of Futurabond $U$ does not make clear the presence of 10-MDP in its composition, the chemical responsible for the development of the material (Danebrock M, personal communication) has already been described; this monomer is present in the Futurabond U composition (Table 1). It is noteworthy that the lack of this monomer was pointed out by Lopes et al. ${ }^{19}$ as the main cause for the lower results found in their study.

Because few clinical studies have been found in the literature with the use of universal adhesives-with or without this $10-\mathrm{MDP}$ monomer-it cannot be stated that this was the real reason for the differences found, and therefore, the authors believe that more clinical studies with different universal adhesive systems with different formulations need to 
be performed. This is also to prove the clinical quality of these new adhesive systems.

Another important finding of the present study were the marginal adaptation data. Although these data are still initial and there is no difference between the four different techniques of application of the Futurabond U adhesive system, the low percentage of marginal failures found in this study $(12 \%)$ is remarkable in comparison with previous studies (38\% in Mena-Serrano et al. ${ }^{16}$ and 39\% in Lopes et $\left.a l^{19}\right)$. Several factors may be involved in the good marginal adaptation of a resin composite to the cavity. ${ }^{38}$ However, in this specific case, the resin composite Admira Fusion was used in caps and was applied directly (with the aid of a Centrix syringe) to the cavity and not in syringes as in previous studies, ${ }^{16,17,19}$ thereby facilitating their insertion into the cavity and consequently decreasing the presence of voids and porosities in the final restorations. ${ }^{39}$

Although, to the best of our knowledge, the effects of the insertion of resin composites in caps or syringes on the clinical performance of composite resin restorations are not known, this is the only plausible explanation for the lower percentage of marginal adaptation problems in the present study in which Admira Fusion was used.

It is important to mention that these percentages of marginal adaptation failures have been increasingly observed due to the use of a more specific evaluation criteria, known as FDI, as in the present study. ${ }^{16,40}$ Most of these defects are clinically acceptable and easily solved with a re-polishing of the restorations. ${ }^{41}$ Future long-term clinical follow-up studies are still necessary to prove the initial results obtained.

\section{Conclusion}

The clinical performance of the Universal Adhesive Futurabond $U$ associated with the Admira Fusion unidoses was found to be safe and shows promise after six months of clinical evaluation when applied in non-carious cervical lesions; Within the limitations of this study, the six-month clinical behavior of Futurabond U (VOCO) was not dependent on the bonding strategy employed.

\section{References}

1- Diniz AC, Bandeca MC, Pinheiro LM, Almeida Jr LJS, Torres CR, Borges AH, et al. Influence of Different Etching Modes on Bond Strength to Enamel using Universal Adhesive Systems. J Contemp Dent Pract. 2016;17(10):820-5.

2- Van Meerbeek B, Yoshihara K, Yoshida Y, Mine A, De Munck J. State of the art of self-etch adhesives. Dent Mater. 2011;27(1):17-28.

3- Carvalho RM, Chersoni S, Frankenberger R, Pashley DH, Prati C, Tay FR. A challenge to the conventional wisdom that simultaneous etching and resin infiltration always occurs in self-etch adhesives. Biomaterials. 2005;26(9):1035-104.

4- Perdigão J, Reis A, Loguercio AD. Dentin adhesion and MMPs: a comprehensive review. J Esthet Dent. 2013;25(4):219-41.

5- Ozer F, Blatz MD. Self-Etch and Etch-and-Rinse Adhesive Systems in Clinical Dentistry. Compend Contin Educ Dent. 2013;34(1):12-24.

6- Szesz A, Parreiras S, Reis A, Loguercio A. Selective enamel etching in cervical lesions for self-etch adhesives: A systematic review and meta-analysis. J Dent. 2016;53(1):1-11.

7- Erickson RL, Barkmeier WW, Latta MA. The role of etching in bonding to enamel: a comparison of self-etching and etch-and-rinse adhesive systems. Dent Mater. 2009;25(11):1459-67.

8- Van Landuyt KL, Peumans M, De Munck J, Lambrechts P, Van Meerbeek B. Extension of a one-step self-etch adhesive into a multi-step adhesive. Dent Mater. 2006;22(6):533-44.

9- Hanabusa M, Mine A, Kuboki T, Momoi Y, Van Ende A, Van Meerbeek B, et al. Bonding effectiveness of a new 'multi-mode' adhesive to enamel and dentine. J Dent. 2012;40(6):475-84.

10- Perdigão J, Sezinando A, Monteiro PC. Laboratory bonding ability of a multi-purpose dentin adhesive. Am J Dent. 2012;25(3):153-8.

11- Lopes LS, Malaquias P, Calazans FS, Reis A, Loguercio A, Barceleiro M. Clinical strategies using universal adhesive systems: literature review with case report. Rev Bras Odont. 2016;73(2):173-7.

12- Munõz MA, Luque-Martinez I, Hass V, Reis A, Loguercio AD, Bombarda NH. Immediate bonding properties of universal adhesives to dentine. J Dent. 2013;41(5):404-11.

13- Loguercio AD, Munõz MA, Luque-Martinez I, Hass V, Reis A, Perdigão J. Does active application of universal adhesives to enamel in self-etch mode improve their performance? J Dent. 2015;43(9):1060-70.

14- Munõz MA, Luque-Martinez I, Malaquias P, Hass V, Reis A, Campanha NH, et al. In vitro longevity of bonding properties of universal adhesives to dentin. Oper Dent. 2015;40(3):282-92.

15- Marchesi G, Frassetto A, Mazzoni A, Apolonio F, Diolosà M, Cadenaro M, et al. Adhesive performance of a multi-mode adhesive system: 1-year in vitro study. J Dent. 2014;42(2):603-12.

16- Mena-Serrano A, Kose C, De Paula EA, Tay LY, Reis A, Loguercio A, et al. A new universal simplified adhesive: 6-month clinical evaluation. J Esthet Restor Dent. 2013;25(1):55-69.

17- Lawson NC, Robles A, Fu CC, Lin CP, Sawlani K, Burgess JO. Two-year clinical trial of a universal adhesive in total-etch and self-etch mode in non-carious cervical lesions. J Dent. 2015;43(10):1229-34.

18- Loguercio AD, de Paula EA, Hass V, Luque-Martinez I, Reis A, Perdigão J. A new universal simplified adhesive: 36-Month randomized double-blind clinical trial. J Dent. 2015;43(9):1083-92.

19- Lopes LS, Calazans FS, Hidalgo R, Buitrago LL, Gutierrez F, Reis A, et al. Sixmonth follow-up of cervical composite restorations placed with a new universal adhesive system: A randomized clinical trial. Oper Dent. 2016;41(5):465-80. 20- Schulz KF, Altman DG, Moher D, CONSORT Group. CONSORT 2010 statement: updated guidelines for reporting parallel group randomised trials. Int J Surg. 2011;9(8):672-7.

21- Zander-Grande C, Ferreira SQ, da Costa TR, Loguercio AD, Reis A. Application of etch-and-rinse adhesives on dry and rewet dentin under rubbing action: a 24-month clinical evaluation. J Am Dent Assoc. 2011;142(7):828-35.

22- Peumans M, De Munck J, Mine A, Van Meerbeek B. Clinical effectiveness of contemporary adhesives for the restoration of non-carious cervical lesions. A systematic review. Dent Mater. 2014; 30(10):1089-103.

23- Swift EJ Jr, Perdigão J, Heymann HO, Wilder AD Jr, Bayne SC, May KN Jr, et al. Eighteen-month clinical evaluation of a filled and unfilled dentin adhesive. J Dent. 2001;29(1):1-6.

24- Hickel R, Roulet JF, Bayne S, Heintze SD, Mjör IA, Peters M, et al. Recommendations for conducting controlled clinical studies of dental restorative materials. Science Committee Project 2/98--FDI World Dental Federation study design (Part I) and criteria for evaluation (Part II) of direct and indirect restorations including onlays and partial crowns. J Adhes Dent. 2007;9 Suppl 1:121-47. 25- Hickel R, Peschke A, Tyas M, Mjor I, Bayne S, Peters M, et al. FDI World Dental Federation: Clinical criteria for the evaluation of direct and indirect restorations-Update and clinical examples. Clin Oral Investig. 2010;14(4):349-66. 26- American Dental Association Council on Scientific Affairs. Acceptance Program Guidelines: Dentin and Enamel Adhesive Materials American Dental Association, Chicago; 2001.

27- Pashley DH, Tay FR, Breschi L, Tjaderhane L, Carvalho RM, Carrilho M, et al. State of the art etch-and-rinse adhesives. Dent Mater. 2011;27(1):1-16. 
28- Pashley DH, Tay FR, Carvalho RM, Rueggeberg FA, Agee KA, Carrilho M, et al. From dry bonding to water-wet bonding to ethanol-wet bonding. A review of the interactions between dentin matrix and solvated resins using a macromodel of the hybrid layer. Amer J Dent. 2007;20(1):7-20.

29- Tay FR, Pashley DH. Have dentin adhesives become too hydrophilic? J Can Dent Assoc. 2003;69(11):726-31.

30- Malacarne J, Carvalho RM, de Goes MF, Svizero N, Pashley DH, Tay FR, et al. Water sorption/solubility of dental adhesive resins. Dent Mater. 2006;22(10):973-80. 31- Pashley DH, Tay FR, Yiu C, Hashimoto M, Breschi L, Carvalho RM, et al. Collagen degradation by host-derived enzymes during aging. J Dent Res. 2004;83(3):216-21.

32- Brackett MG, Li N, Brackett WW, Sword RJ, Qi YP, Niu LN, et al. The critical barrier to progress in dentine bonding with the etch-and-rinse technique. J Dent. 2011;39(3):238-48.

33- Perdigão J, Carmo AR, Geraldeli S. Eighteen-month clinical evaluation of two dentin adhesives applied on dry vs moist dentin. J Adhes Dent. 2005;7(3):253-8.

34- Loguercio AD, Raffo J, Bassani F, Balestrini H, Santo D, do Amaral RC, et al. 24-month clinical evaluation in non-carious cervical lesions of a two-step etch-and-rinse adhesive applied using a rubbing motion. Clin Oral Investig.
2011;15(4):589-96.

35- Yoshida Y, Van Meerbeek B, Nakayama Y, Yoshioka M, Snauwaert J, Abe Y, et al. Adhesion to and decalcification of hydroxyapatite by carboxylic acids. J Dent Res. 2001;80(6):1565-69.

36- Van Landuyt KL, Snauwaert J, De Munck J, Peumans M, Yoshida Y, Poitevin A, et al. Systematic review of the chemical composition of contemporary dental adhesives. Biomaterials. 2007;28(26):3757-85.

37- Labella R, Lambrechts P, Van Meerbeek B, Vanherle G. Polymerization shrinkage and elasticity of flowable composites and filled adhesives. Dent Mater. 1999;15(2):128-37.

38- Opdam NJ, Roeters JJ, Joosten M, Veeke Ov. Porosities and voids in Class I restorations placed by six operators using a packable or syringable composite. Dent Mater. 2002;18(1):58-63

39- de Paula EA, Tay LY, Kose C, Mena-Serrano A, Reis A, Perdigão J, et al. Randomized clinical trial of four adhesion strategies in cervical lesions: 12-month results. Int J Esthet Dent. 2015;10(1):122-45.

40- Hickel R, Brüshaver K, Ilie N. Repair of restorations--criteria for decision making and clinical recommendations. Dent Mater. 2013;29(1):28-50.

\section{Mini Curriculum and Author's Contribution}

1. Elisa Gomes de Albuquerque - DDS. Contribution: bibliographical research, clinical restorative procedures in UFF, manuscript writing.

2. Flavio Warol - DDS and MSD. Contribution: clinical restorative procedures in UFF.

3. Fernanda Signorelli Calazans - DDS and PhD. Contribution: bibliographical research, blinding and randomization procedures, and clinical examination procedures.

4. Luiz Augusto Poubel - DDS and MSD. Contribution: bibliographical research, and clinical examination procedures.

5. Stella Soares Marins - Undergraduate Student. Contribution: bibliographical research and clinical procedures.

6. Thalita Matos - DDS and MSc. Contribution: clinical restorative procedures in UEPG.

7. Taise Hanzen - DDS and MSc. Contribution: clinical restorative procedures in UEPG.

8. Marcos de Oliveira Barceleiro - DDS and PhD. Contribution: manuscript writing, manuscript review, clinical examination procedures, UFF study director and paper submission.

9. Alessandro Dourado Loguercio - DDS and PhD. Contribution: manuscript writing, manuscript review, statistical analysis, clinical examination procedures, and UEPG study director.

Submitted: 08/18/2017 / Accepted for publication: 10/17/2017

\section{Corresponding Author}

Marcos de Oliveira Barceleiro

E-mail: marcosbarceleiro@gmail.com 